\title{
The role of arthroscopy in the diagnosis of concomitant soft tissue injuries in scaphoid fractures and the effect of concomitant soft tissue injuries and fracture comminution on outcomes: A case-control study
}

\author{
Ali Özdemir, $\mathrm{MD}^{1}\left(\mathbb{D}\right.$, Anıl Pulatkan, $\mathrm{MD}^{2} \varpi$, Ebubekir Eravsar, $\mathrm{MD}^{3}\left(\mathbb{D}\right.$, Mehmet Ali Acar, $\mathrm{MD}^{3}$ (1) \\ 1Department of Hand Surgery, Gazi Yaşargil Training and Research Hospital, Diyarbakır, Turkey \\ ${ }^{2}$ Department of Orthopedics and Traumatology, Bezmialem Vakıf University Hospital, Istanbul, Turkey \\ ${ }^{3}$ Department of Orthopedics and Traumatology, Selçuk University Faculty of Medicine, Konya, Turkey
}

Arthroscopy-assisted fixation techniques have been used successfully for the treatment of intra-articular fractures. The most important benefit of arthroscopic fracture fixation over open methods is the direct visualization of the intra-articular space and fracture, thus allowing anatomical fixation and repair of the soft tissues to be performed simultaneously.

Arthroscopy-assisted scaphoid fixation has been described in several studies as a suitable technique to achieve anatomic reduction and improved outcomes. ${ }^{[1-4]}$ This technique is also useful in the identification and intervention of concomitant intra-articular injuries. ${ }^{[2,3]}$ Furthermore, a larger

Received: June 16, 2021

Accepted: October 01, 2021

Published online: November 19, 2021

Correspondence: Ali Özdemir, MD. Gazi Yaşargil Eğitim ve Araştırma Hastanesi El Cerrahisi Bölümü, 21010 Kayapınar, Diyarbakır, Türkiye.

E-mail: aozdmr@hotmail.com

Doi: $10.52312 /$ jdrs.2021.309

Citation: Özdemir A, Pulatkan A, Eravsar E, Acar MA. The role of arthroscopy in the diagnosis of concomitant soft tissue injuries in scaphoid fractures and the effect of concomitant soft tissue injuries and fracture comminution on outcomes: A case-control study. Jt Dis Relat Surg 2021;32(3):729-735.

(อ2021 All right reserved by the Turkish Joint Diseases Foundation

This is an open access article under the terms of the Creative Commons Attribution-NonCommercial License, which permits use, distribution and reproduction in any medium, provided the original work is properly cited and is not used for commercial purposes (http://creativecommons.org/licenses/by-nc/4.0/).

\section{ABSTRACT}

Objectives: This study aims to evaluate the role of arthroscopy in the diagnosis of concomitant injuries, to investigate the relationship between comminution and concomitant injuries, and to analyze the effect of concomitant injuries on functional outcomes in acute and subacute scaphoid fracture.

Patients and methods: Between January 2011 and September 2018. A total of 32 acute scaphoid fracture patients (29 males, 3 females; mean age: $30 \pm 12$ years; range, 18 to 65 years) were retrospectively analyzed. None of them had an obvious ligament injury in the radiological assessment. Functional outcomes were compared between concomitant and non-concomitant injuries and between comminuted and non-comminuted injuries. The percentage of range of motion (ROM), grip, and pinch strength were recorded according to the contralateral extremity to detect the restriction rate. The Mayo Wrist Score (MWS), the Turkish version of the Quick Disability of the Arm, Shoulder, and Hand (Q-DASH) and Patient-Rated Wrist Evaluation (PRWE) questionnaires were used to evaluate the functional results. Subjective pain was assessed using the Visual Analog Scale (VAS). The relationship between concomitant injuries and comminution was investigated.

Results: There were 13 patients with comminuted fractures. Concomitant injuries were diagnosed in 17 patients. The presence of concomitant injuries was higher in comminuted fractures than in non-comminuted fractures. There was no significant difference between the groups in ROMs. The final follow-up Q-DASH, PRWE, MWS, and VAS scores and the pinch strength of non-comminuted fractures were found to be statistically better than those of comminuted fractures. There were statistically worse Q-DASH, PRWE, MWS, and VAS scores in patients with concomitant injuries.

Conclusion: Arthroscopic scaphoid fracture surgery allows the diagnosis and treatment of concomitant lesions. The functional outcomes of concomitant lesions and comminuted fractures seem to be worse than those of others, while the ROM is comparable. Keywords: Arthroscopy, comminuted, fractures, injury, scaphoid bone, therapeutic use, wrist injuries. 
and detailed visualization of the fracture line by arthroscopy is useful for correct positioning of the guidewire and for assessing the absence of screw protrusion in the joint. It has been shown that arthroscopy is more useful than fluoroscopy in different joints in the anatomical reduction of articular fractures..$^{[5-8]}$ Therefore, we routinely prefer using arthroscopy to evaluate scaphoid fracture reduction.

The primary objective of this study was to evaluate the role of arthroscopy in the diagnosis of concomitant injuries in acute and subacute scaphoid fracture and to investigate the relationship between comminution of a fracture and concomitant lesions. The secondary objective was to analyze the effect of concomitant injuries on functional outcomes.

\section{PATIENTS AND METHODS}

This single-center, retrospective, case-control study was conducted at Selçuk University Faculty of Medicine, Department of Orthopedics and Traumatology between January 2011 to September 2018. A total of 32 scaphoid fracture patients (29 males, 3 females; mean age: $30 \pm 12$ years; range, 18 to 65 years) were included in the study. Data including age, sex, dominant side, clinical examination, diagnosis, radiological imaging, date of and reports from the surgery, intraoperative videos, postoperative range of motions (ROMs), and Visual Analog Scale (VAS) and functional scores were reviewed from the hospital database. All patients included in the study had an isolated acute or subacute scaphoid fracture within 60 days of being included in the study, all of them underwent arthroscopy-assisted percutaneous fixation surgery. None of the patients had an obvious ligament injury on standard radiographs and computed tomography (CT) scans. In our practice, scaphoid fracture fixation is routinely performed arthroscopically. We have two indications for arthroscopic-assisted scaphoid fixation in acute fractures: (i) young active patients who are willing to provide early mobilization and (ii) patients with displaced scaphoid fractures. We excluded patients with distances between two bones that were more than $2 \mathrm{~mm}$, which can be indicative of an obvious ligament injury on standard radiographs and CT scans. Magnetic resonance imaging (MRI) is not obtained as a standard. Fractures with an obvious ligament injury according to the radiographs, associated with a distal radius fracture or with trans-scaphoid perilunate fracture dislocation were excluded from the study. Additionally, patients who were younger than 18 years, had less than one year of follow-up, or were lost-to-follow-up were excluded. A written informed consent was obtained from each patient. The study protocol was approved by the Selçuk University Faculty of Medicine Ethics Committee (Date/No: 2019/306). The study was conducted in accordance with the principles of the Declaration of Helsinki.

Initially, conventional anteroposterior, lateral, and scaphoid wrist radiographs were taken for all patients. After the diagnosis of scaphoid fracture, wrist CT reconstructions in the coronal and sagittal planes were applied as the standard to understand the characteristics and comminution of the fracture and perform fracture classification. The treating hand surgeon and two other hand surgeons evaluated all radiological examinations to evaluate comminuted fractures on radiographs and CT scans (Figure 1). Although the bone fragment sizes were very small, fractures in patients with any bone fragments detected on CT or X-ray radiographs were evaluated as comminuted fractures. The fractures were categorized according to the Herbert and Fisher classification. ${ }^{[9]}$ The patients were classified into two groups according to concomitant injuries. The correlation between comminution of the fracture and concomitant injuries was analyzed.

\section{Surgical technique}

All patients were operated by a single experienced hand surgeon who is specialized in wrist arthroscopy. Arthroscopy was performed with a 2.4-mm arthroscope (Karl Storz $\mathrm{GmbH}$, Tuttlingen, Germany). The patients' arms were suspended with a hand traction device. The dorsal arthroscopic 3-4, 6R, midcarpal radial (MC-R) and midcarpal ulnar (MC-U) portals were created as standards. Through these portals, the scapholunate (SL), lunotriquetral (LT), radioschaphocapitate (RSC) and triangular fibrocartilage ligament complex (TFCC) and cartilage status were examined (Figure 2). Concomitant ligament and chondral injuries were recorded. Deterioration of integrity on cartilage surfaces, the gap, and the wide mobility of the affected intercarpal joint in the arthroscopic view were pieces of evidence for concomitant injuries. The fracture side was exposed (Figure 3), debrided, and reduced with manipulation of the distal fragment using a probe. The hand was removed from the traction device, and a percutaneous guide wire was placed on the scaphoid using fluoroscopy. The arm was, then, re-suspended. Fracture reduction and the guidewire position were re-examined. If it was not appropriate, the guidewire was re-inserted by re-reduction. Then, percutaneous fracture fixations were performed 

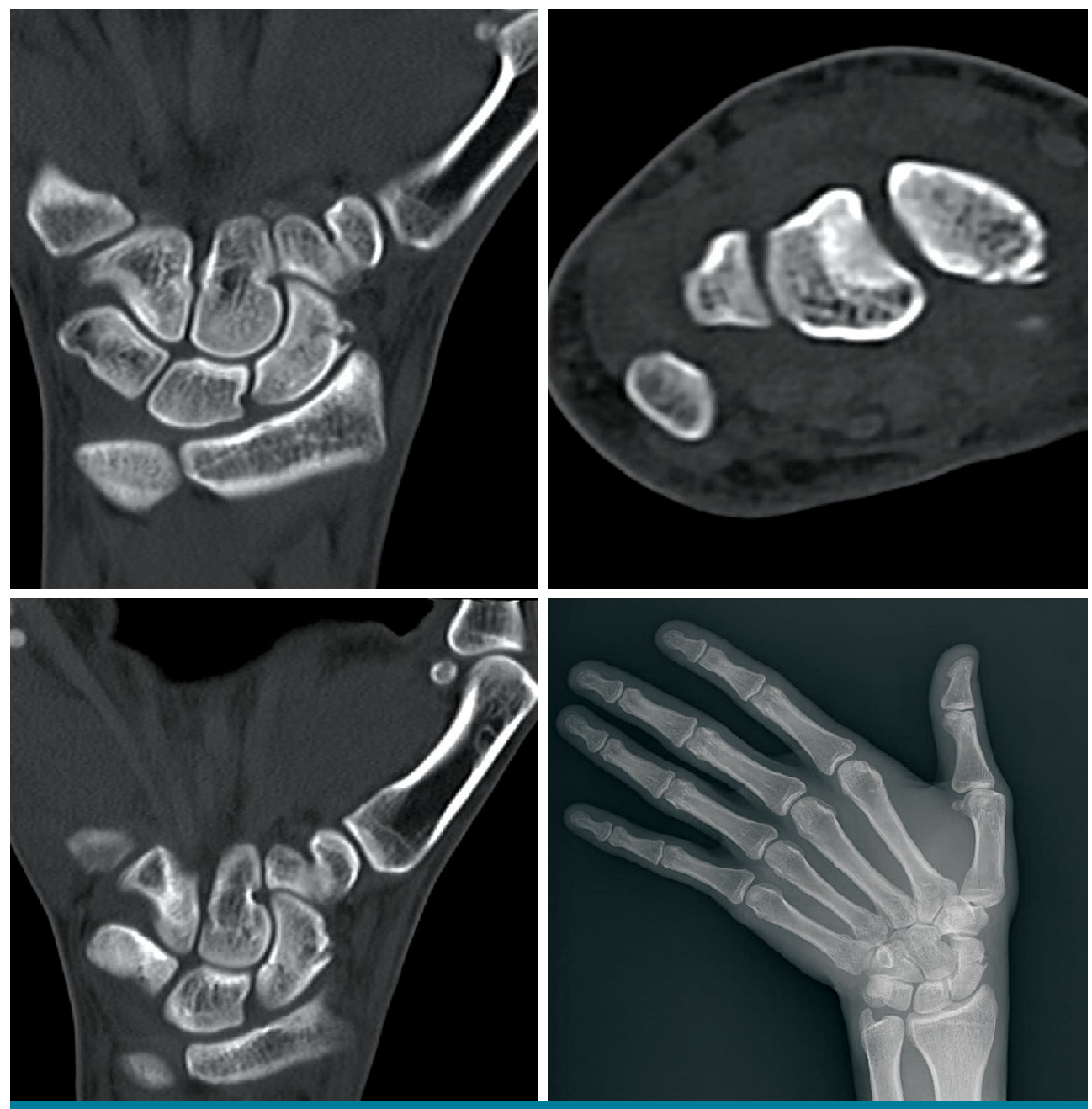

FIGURE 1. A comminuted fracture in computed tomography scans and radiographs.

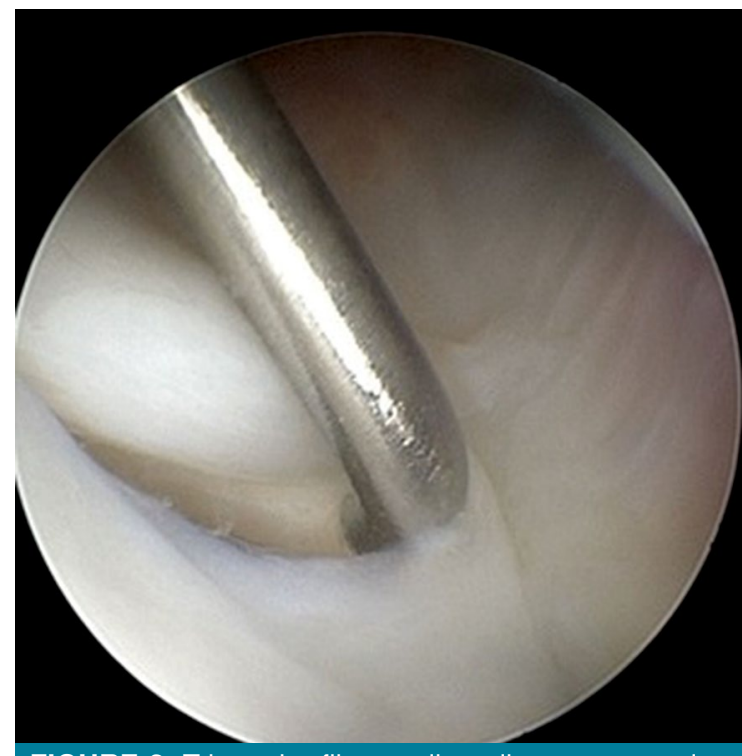

FIGURE 2. Triangular fibrocartilage ligament complex rupture is shown arthroscopically.

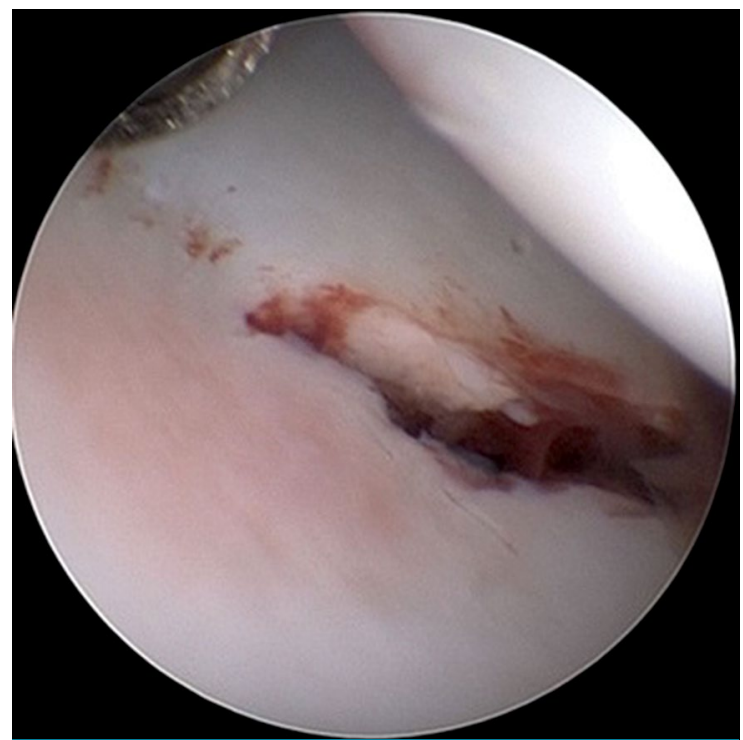

FIGURE 3. Fracture line on the scaphoid. Note that hematoma originating from the fracture. 
with a 3.5-mm headless cannulated compression screw (Tasarım Medikal, Istanbul, Turkey) under guidance from fluoroscopic and arthroscopic images. Concomitant cartilage and ligament injuries were treated as described previously. ${ }^{[10-12]}$ Osteochondral and chondral lesions were debrided and excised. Grade 1 ligament injuries were debrided. Grade 2-3 ligament injuries were treated with arthroscopic dorsal capsulodesis. Central and combined TFCC injuries were debrided, and peripheral injuries were arthroscopically repaired with two absorbable (polydioxanone) sutures through drill holes from the distal ulna.

\section{Postoperative rehabilitation}

All patients underwent follow-up at two weeks and six weeks, and monthly until the union was achieved and, when clinically indicated. The patients with isolated scaphoid fractures or concomitant chondral injuries were immobilized with shortarm casts for four weeks. The patients with TFCC injuries were immobilized with long-arm casts for four weeks. The patients with repaired SL or LT ligament tears were immobilized with a short-arm cast for six weeks. All patients were allowed to perform heavy loading of the hand and wrist after bone union was achieved.

\section{Clinical evaluation}

All clinical evaluations were performed by a single hand surgeon. The wrist flexion-extension (FE) and

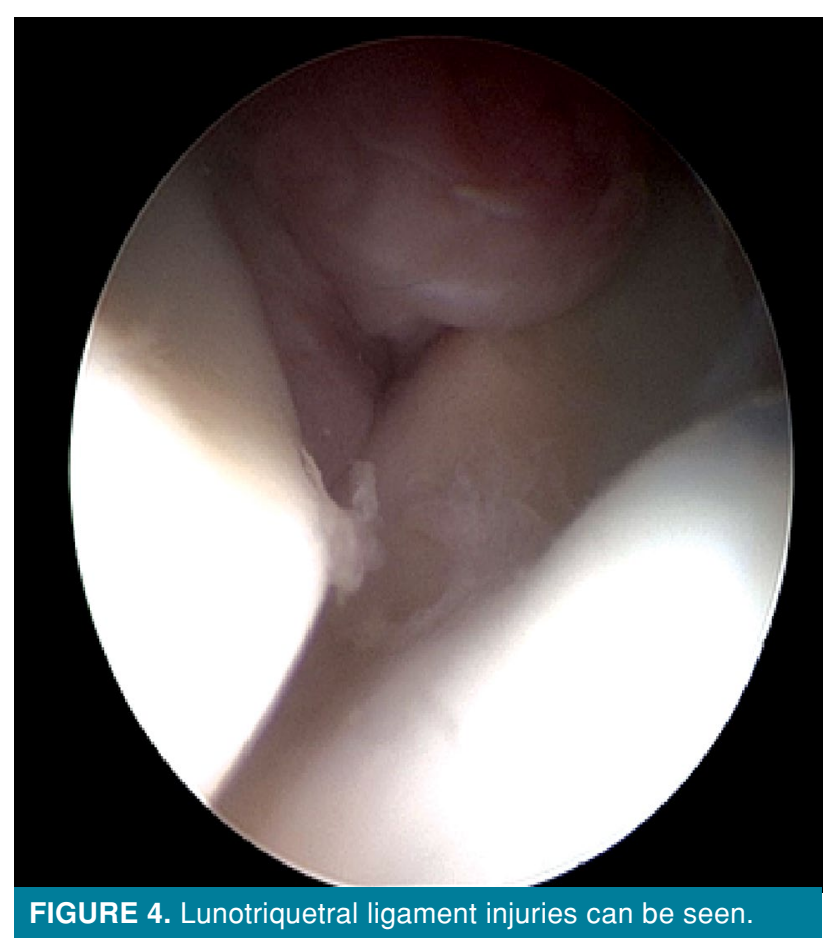

radial-ulnar deviation (RUD) ROM arc were measured with a goniometer. A Jamar hand dynamometer (Baseline ${ }^{\circledR}$ hydraulic hand dynamometer; Irvington, NY, USA) was utilized to determine the grip strength, and a pinch gauge (Baseline ${ }^{\circledR}$ hydraulic pinch gauge; Irvington, NY, USA) was used to evaluate the pinch strength. Grip and pinch strengths were measured three times, and the average of these three measurements was taken as the true strength value. The percentage of ROM and strength were recorded according to the contralateral extremity to detect the restriction rate. The Mayo Wrist Score (MWS) ${ }^{[13]}$ and the Turkish version of the Quick Disability of the Arm, Shoulder, and Hand (Q-DASH) ${ }^{[14]}$ and Patient-Rated Wrist Evaluation (PRWE) ${ }^{[15]}$ questionnaires were used to evaluate the functional results. Subjective pain was assessed using the VAS, graded from 0 to 10 .

\section{Statistical analysis}

Statistical analysis was performed using the IBM SPSS version 21.0 software (IBM Corp., Armonk, NY, USA). Continuous variables were expressed in mean \pm standard deviation (SD) or median (minmax), while categorical variables were expressed in number and frequency. Concordance of the continuous data to a normal distribution was tested using the Shapiro-Wilk test. Two-group comparisons were performed using the Mann-Whitney $U$ test and independent samples t-test. Categorical comparisons were performed using the Fisher's exact test. A $p$ value of $<0.05$ was considered statistically significant.

\section{RESULTS}

The mean follow-up was $36 \pm 14$ (range, 12 to 72 ) months. There were two type A2, eight type B1, 12 type B2, and 10 type B3 fractures according to the Herbert and Fisher classification. There were 13 patients with comminuted fractures (Figure 4).

\begin{tabular}{|lc|}
\hline \multicolumn{2}{|c|}{ TABLE I } \\
\multicolumn{2}{|c|}{$\begin{array}{c}\text { Concomitant injuries that cannot be diagnosed by direct } \\
\text { radiography }\end{array}$} \\
\hline Concomitant Injury & $\begin{array}{c}\text { Scaphoid fracture } \\
\text { (n) }\end{array}$ \\
\hline Isolated ligament or cartilage injury & 11 \\
Scapholunate & 1 \\
Lunotriquetral & 4 \\
TFCC & 2 \\
Cartilage injury & 4 \\
Combined ligament injury & 6 \\
Scapholunate + lunotriquetral & 1 \\
Lunotriquetral + TFCC & 5 \\
\hline TFCC: Triangular fibrocartilage complex. & \\
\hline
\end{tabular}




\begin{tabular}{|c|c|c|c|c|c|c|c|c|c|}
\hline & & Compariso & n of comn & $\begin{array}{l}\text { TABLE II } \\
\text { inuted and }\end{array}$ & two-pa & t fractures & & & \\
\hline & & Oomminuted & fracture ( & $=13)$ & No & n-comminute & d fracture & $(n=19)$ & \\
\hline & $\mathrm{n}$ & Mean $\pm S D$ & Median & Min-Max & $\mathrm{n}$ & Mean $\pm S D$ & Median & Min-Max & $p$ \\
\hline Age (year) & & & 30 & $18-65$ & & & 25 & $19-51$ & $0.426 \ddagger$ \\
\hline Sex & & & & & & & & & $1^{*}$ \\
\hline Male & 12 & & & & 17 & & & & \\
\hline Female & 1 & & & & 2 & & & & \\
\hline Dominant side & $10 / 13$ & & & & $15 / 19$ & & & & $1^{*}$ \\
\hline Q-DASH score & & & 11.3 & $2.2-34$ & & & 4.5 & $0-36$ & $<0.001 \ddagger$ \\
\hline PRWE score & & $16 \pm 6.3$ & & & & $12 \pm 4.4$ & & & $0.042 \dagger$ \\
\hline Mayo Wrist score & & & 80 & $75-90$ & & & 85 & $75-95$ & $0.006 \ddagger$ \\
\hline VAS scale & & & 2 & $0-4$ & & & 0 & $0-4$ & $0.022 \ddagger$ \\
\hline FE-ROM (\%) & & & 93 & $64-100$ & & & 96 & $71-100$ & $0.182 \ddagger$ \\
\hline RUD-ROM (\%) & & & 88 & $75-100$ & & & 100 & $75-100$ & $0.383 \ddagger$ \\
\hline Grip strength (\%) & & & 83 & $58-100$ & & & 100 & $54-100$ & $0.147 \ddagger$ \\
\hline Pinch strength (\%) & & & 80 & $67-89$ & & & 100 & $67-100$ & $0.003 \ddagger$ \\
\hline
\end{tabular}

Concomitant ligament and cartilage injuries were diagnosed in $17(53 \%)$ patients. Concomitant injuries are summarized in Table I. Four type B1 (50\%), six type B2 (50\%) and seven type B3 fractures $(70 \%)$ had concomitant injuries. In total, one A2 (50\%), three B1 $(38 \%)$, five B2 $(42 \%)$, and four B3 fractures $(40 \%)$ had comminution. The presence of concomitant injury diagnosis was significantly higher in comminuted fractures $(11 / 13)$ than in two-part fractures $(6 / 19)$ $(\mathrm{p}=0.003)$. The bone union was achieved in 30 patients and it was confirmed with CT. There were nonunion in two patients.

\begin{tabular}{|c|c|c|c|c|c|c|c|c|c|}
\hline \multicolumn{10}{|c|}{$\begin{array}{l}\text { TABLE III } \\
\text { parison of concomitant injuries and isolated scaphoid fractures }\end{array}$} \\
\hline & \multicolumn{4}{|c|}{ Comminuted fracture $(n=17)$} & \multicolumn{4}{|c|}{ Isolated scaphoid injury $(n=15)$} & \multirow[b]{2}{*}{$p$} \\
\hline & $\mathrm{n}$ & Mean $\pm S D$ & Median & Min-Max & $\mathrm{n}$ & Mean \pm SD & Median & Min-Max & \\
\hline Age (year) & & & 25 & $18-64$ & & & 27 & $20-65$ & $0.313 \ddagger$ \\
\hline Sex & & & & & & & & & $0.589^{*}$ \\
\hline Male & 16 & & & & 13 & & & & \\
\hline Female & 1 & & & & 2 & & & & \\
\hline Dominant side & $12 / 17$ & & & & $13 / 15$ & & & & $0.403^{*}$ \\
\hline Q-DASH score & & & 9.1 & $2.2-34$ & & & 4.5 & $0-36$ & $0,027 \ddagger$ \\
\hline PRWE score & & $15.5 \pm 5.5$ & & & & $11.5 \pm 4.8$ & & & $0.035 \dagger$ \\
\hline Mayo Wrist score & & & 80 & $75-95$ & & & 90 & $85-95$ & $0.001 \ddagger$ \\
\hline VAS scale & & & 2 & $0-4$ & & & 0 & $0-2$ & $0,01 \ddagger$ \\
\hline FE-ROM (\%) & & & 93.1 & $64-100$ & & & 95.7 & $71-100$ & $0,261 \ddagger$ \\
\hline RUD-ROM (\%) & & & 90 & $75-100$ & & & 100 & $75-100$ & $0,455 \ddagger$ \\
\hline Grip strength (\%) & & & 83.3 & $57.9-100$ & & & 100 & $53.9-100$ & $0,176 \ddagger$ \\
\hline Pinch strength (\%) & & & 81.8 & $66.7-100$ & & & 83.3 & $66.7-100$ & $0,682 \ddagger$ \\
\hline
\end{tabular}


The final follow-up Q-DASH $(\mathrm{p}<0.001)$, PRWE $(\mathrm{p}=0.042)$, MWS $(\mathrm{p}=0.006)$, and VAS $(\mathrm{p}=0.022)$ scores and the pinch strength $(\mathrm{p}=0.003)$ of non-comminuted fractures were statistically significantly improved than those of comminuted fractures (Table II). The Q-DASH ( $p=0.027)$, PRWE ( $\mathrm{p}=0.035)$, MWS $(\mathrm{p}=0.001)$, and VAS $(\mathrm{p}=0.01)$ scores were statistically significantly worse in patients with concomitant injuries than in patients without concomitant injuries (Table III). There was no significant ROM difference between the groups.

\section{DISCUSSION}

Since the scaphoid fracture is an intra-articular fracture, scaphoid fixation has been performed for a long time, accompanied by wrist arthroscopy, to ensure anatomic reduction of the fracture. According to the results of the current study, scaphoid comminution was associated with worse functional outcomes and additional injuries. The severity of the trauma could increase comminution and, thus, additional injuries. Functional outcomes were worse in the scaphoid fractures with additional injuries. There was no significant difference in ROM between patients with comminuted fractures or additional injuries and those without. Nevertheless, the number of studies is limited regarding the necessity of treatment of additional injuries or whether they are overdiagnosed by arthroscopy and we need more researches to elucidate this issue.

The diagnosis of additional soft tissue pathologies has increased with the increasing use of arthroscopy for intra-articular fractures, as well as in wrist arthroscopy. In contrast, additional lesions may be overdiagnosed by arthroscopy in scaphoid fractures, and the distinction of laxity from instability is important. ${ }^{[16]}$ In the literature, the incidence of concomitant injuries accompanying scaphoid fractures varies. ${ }^{[3,16,17]}$ Jørgsholm et al. ${ }^{[17]}$ reported $29 \mathrm{SL}$, eight LT, and 11 TFCC injuries in 34 out of 41 acute scaphoid waist fractures. Della Rosa et al. ${ }^{[16]}$ found that 20 of 29 acute scaphoid fractures had concomitant SL injuries. In another study, 52 patients with acute scaphoid fractures were evaluated. A total of $18(34 \%)$ patients had an associated carpal ligament injury (4 SL ligament injuries, 8 LT ligament tears, 2 combined tears, and 3 TFCC tears). ${ }^{[18]}$ However, Thomsen and Falcone ${ }^{[19]}$ found no SL lesions in 18 scaphoid fractures that were treated with arthroscopic-assisted percutaneous fixation. The variable incidence of concomitant lesions in the literature may be due to the non-homogenous patient groups, the surgeon's indication selection, the acute or chronic nature of the fracture, and the energy mechanism status of the injury. In the current study, there were 17 concomitant injuries in 32 patients.

The ligamentous structures are likely to play an important role in the stability of scaphoid fractures. There is no consensus about the simultaneous treatment of concomitant intra-articular lesions while performing scaphoid fracture surgery. Many surgeons treat concomitant ligament or chondral injuries conservatively in a thumb spica cast. Kang et al. ${ }^{[20]}$ concluded that there was no significant functional outcome difference between treated and non-treated intra-articular concomitant injuries that were incidentally diagnosed during arthroscopic scaphoid fracture surgery. However, non-treated concomitant ligament or chondral injuries can cause symptomatic carpal instability and chronic wrist pain. In addition, there is no consensus that concomitant lesions worsen patient outcomes. ${ }^{[16]}$ In our study, the patients with concomitant injuries had worse functional outcomes than patients who did not have concomitant injuries.

Comminuted fractures were also associated with poor results. Buijze et al. ${ }^{[21]}$ reported that comminuted fractures were associated with displacement and instability. These fractures were classified as unstable and difficult to repair in previous studies. ${ }^{[9]}$ Clementson et al. ${ }^{[22]}$ treated 23 non- or minimally displaced scaphoid waist fractures with cast immobilization. Nineteen fractures in this group united after six weeks. Four fractures that united later than six weeks were comminuted fractures (three of them united after 10 weeks and one of them after 14 weeks). Grewal et al. ${ }^{[23]}$ reported that comminution was not associated with low union rates, but it significantly increased the time-to-union in their conservatively treated case series. In the current study, a significant difference was found between comminuted fractures and concomitant intra-articular injuries $(\mathrm{p}=0.003)$. This suggests that the severity of trauma may lead to an increase in concomitant intra-articular injuries. The delayed union rates reported in previous studies may be explained by additional intra-articular injuries or the severity of trauma. In contrast to the fact that comminuted fractures in conservatively treated case series were associated with delayed union, we did not observe a significant difference in union time in our case series. Additionally, we found worse functional outcomes with comminuted fractures than with non-comminuted fractures. Neither condition was superior in terms of ROM 
(FE-ROM, $\mathrm{p}=0.182 ;$ RUD-ROM, $\mathrm{p}=0.383$ ) and grip power $(p=0,147)$. It is not an unexpected situation that comminuted fractures are likely, due to higher energy injuries, to include additional injuries at a higher rate and may take longer to heal. Poor functional outcomes may be also associated with the coexistence of comminuted fractures and additional injuries and, therefore, longer-term immobilization, but additional prospective studies are required to confirm this.

The main limitations of this study include its retrospective design and small sample size. Also, the functional outcomes of conservatively treated lesions are uncertain, as we treated the accompanying lesions in all patients. In addition, the concomitant lesions were diagnosed by a single surgeon who performed all surgeries. The intra- and inter-observer reliability of the diagnosis was unable to be calculated.

In conclusion, arthroscopy-assisted scaphoid fracture surgery is a surgical method that allows the diagnosis and treatment of concomitant lesions with satisfactory results. Although the functional results of concomitant lesions and comminuted fractures seem to be worse, the ROM is comparable. Further researches are needed to examine the necessity of additional imaging studies such as MRI and CT in the evaluation of concomitant injuries accompanying the scaphoid fractures and whether this would be beneficial.

\section{Declaration of conflicting interests}

The authors declared no conflicts of interest with respect to the authorship and/or publication of this article.

\section{Funding}

The authors received no financial support for the research and/or authorship of this article.

\section{REFERENCES}

1. Hsiung W, Huang HK, Wang JP, Chang MC, Huang YC. Arthroscopic realignment and osteosynthesis of unstable scaphoid nonunion with cancellous bone graft from the ipsilateral radius. Int Orthop 2021;45:191-7.

2. Wong WC, Ho PC. Arthroscopic management of scaphoid nonunion. Hand Clin 2019 ;35:295-313.

3. Caloia MF, Gallino RN, Caloia H, Rivarola H. Incidence of ligamentous and other injuries associated with scaphoid fractures during arthroscopically assisted reduction and percutaneous fixation. Arthroscopy 2008;24:754-9.

4. Slade JF, Lozano-Calderón S, Merrell G, Ring D. Arthroscopic-assisted percutaneous reduction and screw fixation of displaced scaphoid fractures. J Hand Surg Eur Vol 2008;33:350-4.

5. Del Piñal F. Technical tips for (dry) arthroscopic reduction and internal fixation of distal radius fractures. J Hand Surg
Am 2011;36:1694-705.

6. Atesok K, Doral MN, Whipple T, Mann G, Mei-Dan O, Atay OA, et al. Arthroscopy-assisted fracture fixation. Knee Surg Sports Traumatol Arthrosc 2011;19:320-9.

7. MacIntyre NJ, Dewan N. Epidemiology of distal radius fractures and factors predicting risk and prognosis. J Hand Ther 2016;29:136-45.

8. Varitimidis SE, Basdekis GK, Dailiana ZH, Hantes ME, Bargiotas K, Malizos K. Treatment of intra-articular fractures of the distal radius: Fluoroscopic or arthroscopic reduction? J Bone Joint Surg [Br] 2008;90:778-85.

9. Herbert TJ, Fisher WE. Management of the fractured scaphoid using a new bone screw. J Bone Joint Surg [Br] 1984;66:114-23.

10. Lindau T. Arthroscopic evaluation of associated soft tissue injuries in distal radius fractures. Hand Clin 2017;33:651-8.

11. Acar MA, Özdemir A, Eravsar E. Arthroscopic dorsal capsulodesis for isolated lunotriquetral interosseous ligament injuries. J Hand Surg Eur Vol 2021;46:510-5.

12. Mathoulin C, Gras M. Role of wrist arthroscopy in scapholunate dissociation. Orthop Traumatol Surg Res 2020;106(1S):S89-S99.

13. Slutsky DJ. Outcomes assessment in wrist surgery. J Wrist Surg 2013;2:1-4.

14. Koldas Dogan S, Ay S, Evcik D, Baser O. Adaptation of Turkish version of the questionnaire Quick Disability of the Arm, Shoulder, and Hand (Quick DASH) in patients with carpal tunnel syndrome. Clin Rheumatol 2011;30:185-91.

15. Öztürk Ö, Sarı Z, Özgül B, Taşyıkan L. Validity and reliability of the Turkish "Patient-Rated Wrist Evaluation" questionnaire. Acta Orthop Traumatol Turc 2015;49:120-5.

16. Della Rosa N, Duca V, Lancellotti E, Pilla F, Panciera A, Adani R. Scaphoid fractures with scapholunate ligament involvement: Instability or ligamentous laxity? Role of arthroscopy and pinning. Musculoskelet Surg 2019;103:263-8.

17. Jørgsholm P, Thomsen NO, Björkman A, Besjakov J, Abrahamsson SO. The incidence of intrinsic and extrinsic ligament injuries in scaphoid waist fractures. J Hand Surg Am 2010;35:368-74.

18. Wong TC, Yip TH, Wu WC. Carpal ligament injuries with acute scaphoid fractures - a combined wrist injury. J Hand Surg Br 2005;30:415-8.

19. Thomsen L, Falcone MO. Lesions of the scapholunate ligament associated with minimally displaced or nondisplaced fractures of the scaphoid waist. Which incidence? Chir Main 2012;31:234-8.

20. Kang HJ, Chun YM, Oh WT, Koh IH, Lee SY, Choi YR. The effect of debridement of coexisting partial ligament injuries on outcomes following arthroscopic osteosynthesis for minimally displaced scaphoid nonunions. J Hand Surg Am 2016;41:e135-42.

21. Buijze GA, Jørgsholm $P$, Thomsen NO, Björkman A, Besjakov J, Ring D. Factors associated with arthroscopically determined scaphoid fracture displacement and instability. J Hand Surg Am 2012;37:1405-10.

22. Clementson M, Jørgsholm P, Besjakov J, Björkman A, Thomsen N. Union of scaphoid waist fractures assessed by CT scan. J Wrist Surg 2015;4:49-55.

23. Grewal R, Suh N, Macdermid JC. Use of computed tomography to predict union and time to union in acute scaphoid fractures treated nonoperatively. J Hand Surg Am 2013;38:872-7. 